\section{Síndrome de Procusto en la Medicina}

\section{Procrustes syndrome in Medicine}

\section{Señor Editor:}

Procusto, en la mitología griega, o Procrustes, literalmente "estirador", también llamado Damastes ("controlador"), hijo de Poseidón, fue encargado de una posada en Ática (región al sur de Grecia) (Figura 1) 1 .

Se caracterizó por su comportamiento amable, complaciente y afectuoso hacia los viajeros, a quienes les ofrecía hospedaje en su casa. Una vez en ella, los invitaba a descansar en su lecho de hierro y, mientras dormían, los amordazaba y amarraba en las cuatro esquinas de la cama para verificar si se ajustaban a la misma ${ }^{1}$.

Si el viajante poseía una estatura mayor que el lecho, le cortaba las extremidades inferiores o superiores (pies, brazos, cabeza). De lo contrario, le estiraba las piernas a martillazos hasta quedar a la altura del lecho. Con respecto a este punto, existen otras versiones, que afirman que tenía dos camas de diferentes tamaños, una larga y otra corta, y también de que poseía una cama con un mecanismo móvil que la alargaba o acortaba según su deseo y conveniencia ${ }^{2}$.

Murió a manos de Teseo, quien lo enfrentó y lo llevó a una trampa, al lograr que se acostara en su propio lecho para comprobar si su cuerpo encajaba en él, cuando lo hizo, lo ató a la cama y lo torturó para ajustarlo, tal como sufrieron los viajantes bajo su dominio (Figura $1)^{1}$. Matar a Procusto fue la última aventura de Teseo en su viaje desde Trecén (su aldea natal del Peloponeso) hasta Atenas ${ }^{3}$.

Procusto se ha convertido en un sinónimo de uniformidad y su síndrome define la intolerancia a la diferencia. En medicina y otras ciencias, cuando alguien quiere que todo se ajuste a lo que dice o piensa, lo que quiere es que todos se acuesten en el "lecho de Procusto". Esta frase define a una situación tiránica y arbitraria. Se utiliza para referirse o indicar a los individuos que al principio muestran su mejor actitud y comportamiento, pero luego pretenden someter y controlar a las demás personas bajo sus órdenes y pensamientos para alcanzar sus intereses y fines, de la misma forma como Procusto adaptaba el tamaño de sus víctimas en relación con el tamaño de la cama. Se aplica además a aquella falacia seudocientífica en la que se tratan de deformar los datos de la realidad para que se adapten a la hipótesis previa, hecho observado de manera frecuente en medicina. Se menciona también para hablar de la forma y/o longitud de las extremidades, cara, cráneo, etc ${ }^{2,3}$.

Pero el significado que quiero hacer notar y es de frecuente observación en la práctica, es la incapacidad para reconocer como válidas las ideas del otro (al ser superados en nuestros conocimientos), el miedo a ser superados profesionalmente por un subordinado o la 


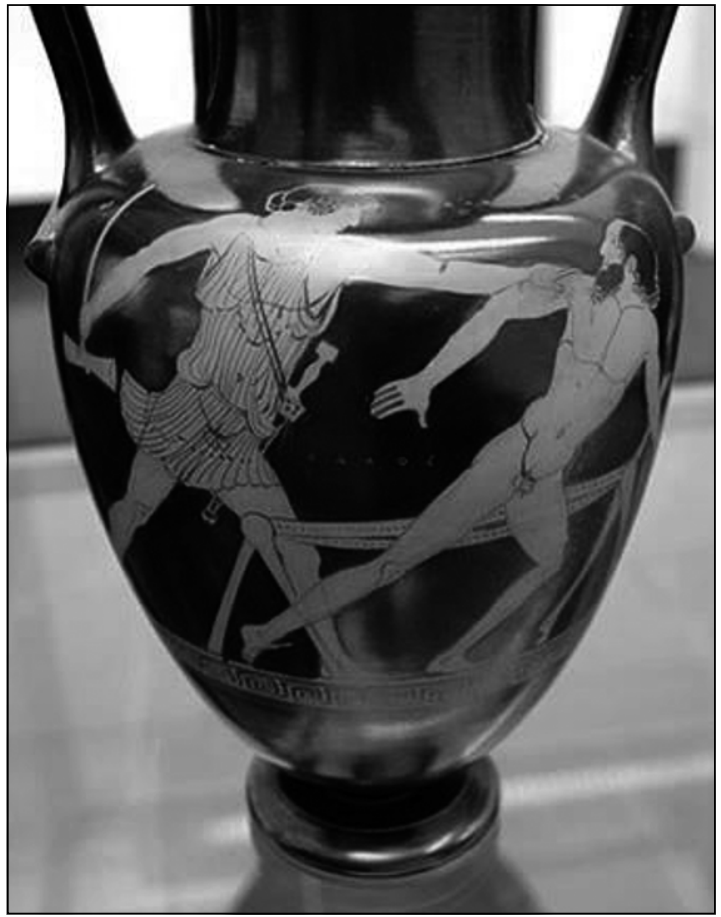

Figura 1. Teseo (vestido con ropas transparentes) y Procusto (casi acostado en su famoso lecho); Ánfora ática de figuras rojas (470 a. C.) pintada por Alquímaco, proveniente de Nola (cerca de Nápoles). En: https://es.wikipedia.org/wiki/Procusto; consultado el 13/1/18.

envidia pueden llevar a algunos directivos o mandos intermedios a eludir su principal responsabilidad, tomar las decisiones más adecuadas para su hospital, dedicándose a cercenar las iniciativas, aportes e ideas de aquellos que pueden dejarles en evidencia (miedo a perder nuestro puesto o ascenso). Como dijo Steve Jobs "No tiene sentido contratar a personas inteligentes $y$ después decirles lo que tienen que hacer. Nosotros contratamos a personas inteligentes para que nos digan qué tenemos que hacer" ${ }^{\text {. }}$. El problema no es tener directivos y/o subordinados que sepan más que nosotros, el problema es no saber gestionar ese talento.

La presencia en profesionales de la salud con este cuadro, que reconocen entre sus subordinados auténticos líderes de opinión que puedan hacerles sombra, padecen también del síndrome de Cronos, que se refiere al miedo patológico de la persona que ocupa un puesto superior, de promover a sus subalternos por temor a ser desplazado o sustituido; su diagnóstico se basa en características de desempeño, temor a delegar, relaciones sociales patológicas, egocentrismo, autoengaño y desarrollo limitado ${ }^{5}$.

En medicina aquel médico que sufre del síndrome de Procusto, o sea que quiere que todo se ajuste a lo que dice o piensa, hace que el que sufra las consecuencias sea el paciente. Debido a que uno debe y tiene que ser abierto a las ideas de los colegas en beneficio de nuestros pacientes. Otro ejemplo de Procusto, es el síndrome de Tonegawa publicado en esta revista que ilustra el fracaso en el freno del entrenamiento de médicos jóvenes ocasionado por médicos de mayor edad, quienes los ven como una competencia a futuro ${ }^{6}$.

La cuestión no está en intentar cambiar a un Procusto, sino en conseguir que mantenga cierto grado de flexibilidad y una actitud más adaptable a los cambios. La flexibilidad aportaría ese punto de autocrítica que le haría buscar alternativas, tomar la iniciativa, cuestionarse las cosas, sin conformarse con un punto de vista único, el suyo. Una persona flexible es una persona que no solamente se adapta a los cambios, sino que los promueve. Y la adaptabilidad permitiría a los Procustos a asumir y fijar la nueva información, los diferentes conocimientos, las innovaciones, los cambios y los nuevos esquemas de funcionamiento. Con la suficiente capacitación y mentoring, todos tenemos la capacidad de ser flexibles y adaptables: otra cosa es que seamos capaces de equilibrar ambos aspectos para que fluyan de forma positiva.

\section{Pablo Young Servicio de Clínica Médica, Hospital Británico de Buenos Aires, Argentina.}

\section{Referencias}

1. Marco C. Procusto's Syndrome: Dispense with who outstands. En: https://excelencemanagement.wordpress. com/2016/11/17/procusto-syndrome-dispense-with-who-outstands-from-supervisors/; consultado el 13/1/18.

2. Maher D. Standardized interventions in international health: Procrustes, where are you now? Trop Med Int Health 2009; 14: 1162-4.

3. Wentzell PD, Hou S, Silva CS, Wicks CC, Pimentel MF. Procrustes rotation as a diagnostic tool for projection pursuit analysis. Anal Chim Acta 2015; 877: 51-63.

4. Díaz J. 15 Frases celebres de Steve Jobs. http://www. negociosyemprendimiento.org/2011/08/15-frases-celebres-de-steve-jobs.html; consultado el 14/1/18.

5. Flores-Sandí G. Síndrome de Cronos. Acta Médica Costarricense 2011; 53: 121-8.

6. Young P. Síndrome de Tonegawa. Rev Med Chile 2013; 141: 678-9.

Correspondencia a:

Pablo Young

Hospital Británico. Perdriel 74 (1280) Buenos Aires, Argentina. Tel 541143096400 Fax 541143043393

pabloyoung2003@yahoo.com.ar 